\title{
Research on Cultural Diversity and Intercultural Communication under the New Media Environment
}

\author{
Zhou Jian ${ }^{1}$ \\ ${ }^{1}$ Wuhan Donghu University, Wuhan, Hubei, 430070
}

Keywords: new media environment; intercultural communication; cultural diversity

\begin{abstract}
Under the influence and promotion of Internet technology, the process of economic and social development has progressed by leaps and bounds. In particular, the construction of informatization is changing with each passing day. In a sense, modern information technology, marked by the Internet, has truly turned our planet into a small village. There are many influential factors for cultural diversity and intercultural communication, including not only nonverbal but also linguistic and cognitive aspects. Its constraints or obstacles are mainly manifested in the traditional aspects of the direction of the scene and the individual's ability to form some kind of constraints. In the context of new media, cultural diversity and intercultural communication inspire communicators have a strong desire to communicate. At the same time, communicators in the process of exchange can continue to enrich the appropriate skills and develop their own knowledge, which are the advantages of cross-cultural communication and cultural diversity.
\end{abstract}

\section{Introduction}

In the context of the globalization of the world, various types of emerging media are breaking the barriers that hinder cultural development, going abroad and going global. Although different countries may not have the same cultural background and different countries may be far away from each other, it is because of the modern Internet technology that cross-cultural exchanges have become a reality. [1] However, we must be soberly aware that such cultural diversity and cross-cultural exchanges still face many challenges and many problems need to be studied and solved.

\section{Analysis of Unfavorable Factors of Cultural Diversity and Intercultural Communication under the New Media Environment}

\subsection{The limitation of individual ability}

From individual's point of view, some participants in the process of cross-cultural communication are not strongly desired to participate. In general, people are only accustomed to matters which are familiar to themselves, while appear to be relatively cold to unfamiliar things, especially to those matters of risk. This kind of situation has also been vividly embodied in cultural diversity and cross-cultural exchange. People's interaction is the same; they want to interact with more familiar things, and stay indifferent to the unfamiliar. In normal process of interpersonal communication, we generally only like to communicate with our residents, and do not like to communicate with foreigners because of language and other problems. [2] This creates an obstacle to intercultural communication, which blocks the exchange of cultures among different nations. The other is the lack of proper knowledge to support their exchange and lack of communication skills. During the process of interpersonal communication, most residents in our country hold the concept of "group". However, most western countries emphasize their personal awareness. Therefore, this will add many problems to the exchange process between China and the western countries.

\subsection{The constraints of communication scene}

In a particular occasion, the factors that form a constraint on normal exchanges are mainly 
manifested in the stage as well as in props and status. If these contents are quoted in the cultural exchange, the exchange will have very different effects if the communication is conducted internally by one of the two countries and the third country. Every country has its own form of exchange. Therefore, it is imperative to respect each other's habits and understand the exchange pattern of each other's country in order to better avoid contradictions and conflicts. [2]

\subsection{The certain degree of obstruction in tradition of history}

The constraints formed by the historical tradition are manifested in the aspects of culture. For a person in a certain cultural environment, the role of culture is quite outstanding. That is to say, to a certain extent, to pre-arrange predictable atmosphere. People implement their own familiar cultural system, so they have the ability to understand this cultural atmosphere. Well, they are no strangers to this culture. However, for cultural phenomena outside this cultural atmosphere, the extra-territorial culture simply looks like a wall of iron and steel, which is hard to be known. The existence of these factors, intangible, further exacerbated the already existing cultural differences. All in all, the differences in values, world outlook and outlook on life have created considerable obstacles to cultural exchanges among people. [2]

\section{The Cultural Diversity under New Media Environment and Analysis of Favorable Factors of Intercultural Communication}

\subsection{Enhance the Desire to Communicate}

Modern network technology makes people's emotions and thoughts have the most efficient expression and enables people have more channels to share their emotions, so once entering the modern network, technology has become an indispensable tool for people. The use of the internet for communication has become an integral part of everyday life. The reason why this happens is that modern web technologies create the conditions for communication in a written manner. Internet text exchange can be protected from other factors, so is not only very convenient for communication and exchange, but also more conducive to the release of people's pressure. Just because of this feature, a lot of people indulge in the network and can not extricate themselves. In particular, some eccentric, taciturn people like to stay online, rather than go into real life. [3]

\subsection{Enhance the Exchange Knowledge}

Through the Internet, we can get a large amount of information resources, including knowledge resources. The Internet carries massive amounts of information, which makes sense for eliminating language and cultural barriers. There are many educational institutions that use digital publishing to carry out language education, especially through tele-teaching to spread knowledge across time and space. This type of education presents an interactive way to make it easier for educators to access educational information. At the same time, it also makes language learning easier and more convenient. Therefore, it is also possible to achieve the free exchange of people, thus making it possible to communicate across cultures. Obstacles other than words also exist, and are extremely deep. The concept and value of different cultures can make a big difference, and the same can be used for a detailed understanding of the new media. For example, in tourism, we can achieve cross-cultural exchanges. Usually, people can get to know the traveling destination through network information before traveling there, for instance to know about the diet, customs, etiquette and so on. [3]

\subsection{Enrich Communication Skills}

Through modern Internet technology, people can well learn and understand the skills of interpersonal communication, and also improve their application skills through network technology in the field of digital television, or in the production of television programs, for example. Emerging online media in the application process for the production and storage of programs have created more convenient conditions, but also create conditions for users to freely choose the program. The 
content being broadcast becomes more direct, which in turn makes the program more sophisticated in craftsmanship. In particular, computer-generated stunt technology can make some cultural scenes and historical scenes have more realistic reflection. For example, the fantasy scene in the "Avatar" create immersive experience for the audience. [4]

\subsection{Promote the Desalination of the Scene}

Digital media has also brought about a reorganization of the social environment, and people are no longer subject to certain fixed points of experience and of course no longer subject to the limitations of the living environment. For this reason, this has become the important theoretical content for many studies on emerging media institutes. In the past because of geographical factors, they are more willing to get together in real life. But in the new media environment, people can get mutual understanding because they communicate online at the same time. This has shown the impact of the emerging media on the people who live in the same virtual environment through the new media [4].

\subsection{Promote the Desalination of Historical Traditions}

In a variety of emerging media environments, considerable changes have taken place in the values and world outlooks. For example, the monopolistic behavior of Microsoft has directly or indirectly led to the convergence of web design patterns in the world. A large number of Internet users have began to use softwares similar to EMAIL to send and receive e-mails and other services. This property of transcending time and space of the Internet has made people's space-time differences smaller and smaller, and barriers to communication have also been gradually broken through. Emerging media also produces a desire to communicate across cultures, for example, using the Internet for game activities.

\section{Analysis of Cultural Diversity and Cultural Unity}

In today's world of ever-intensified cultural exchanges, there are constant conflicts between cultures. If some kind of gap was found in the exchange process, such a gap often became a direct cause of conflict. Confrontation can occur when such conflicts are unavoidable, and even war is possible. However, it must be clearly recognized that there are certainly conflicts between different cultures, but this is not inevitable [4].

The spread across cultures has achieved exceptionally rapid growth, which has emerged as an international trend. This globalization has not resulted in an irreparable rift in the world and no major war. Some academics believe that in today's highly developed online media, there may be the integration of world culture. In this regard, we also need to have a clearer understanding. The unity of culture should not be the direction and purpose of cultural exchange and the harmony and promotion should be embodied in the process of the exchange across cultures. Such a function also proves different cultural characteristics of different countries.

Growing new media have spawned a new culture of intercultural communication that demands not to prevail over other cultures based on their own culture. In particular, we should not replace other cultures with our own culture. We can not replace the weak cultures with more powerful ones. Only in this way can cultural diversity be promoted. [5]

Undoubtedly, the new media is powerful enough to embody the characteristics of different media. Such as international communication, organizational communication and interpersonal communication is very obvious characteristics. What it brings is the humanization of the communication effect, which fully emphasizes the value of individuality. As an emerging medium, it possesses a calculating attribute to different cultures, which is an inevitable trend and requirement of humanization. Therefore, there is no need to worry that the new media will homogenize the culture. 


\section{Practices of Cultural Diversity and Intercultural Communication in the New Media}

As a new form of media, modern online media has increasingly assumed the historic mission of cultural exchange. However, from the current situation, its characteristics and functions have not been brought into full play due to technical and other reasons. With the existing technical support, the advantage of emerging media can be utilized as much as possible to promote the exchange of different cultures, which can be manifested in many aspects. [5]

Taking travel as an example, travel in the past is basically going to the place for local tourism, visitors personally appreciating the scenery. However, in the context of the continuous development of modern Internet technology, more and more people have started their own special tourism. Virtual tourism, which is based on the premise of the reality of tourism under a travel mode to simulate the virtual environment to build, often makes the tourists feel empathy. With regard to virtual travel, the concept was initially used by us after foreign translation, but so far our tourism in this area is still far from perfect. The time we explored was still short and the concept was far from agreement. In the process of deepening the research, it has been increasingly clear in concept and scope. This mode of travel has made it true that people can travel thousands of miles without going out, and even taking pictures of the destination has become a reality. [6]

Some more distinctive outlets have established their own three-dimensional space through the network. Through the virtual protagonist, three-dimensional space can be more carved and provides sightseeing service. Based on it, you can travel where you want without leaving home to have a scenic tour. For example, the tastes of exotic cuisine in different countries and the feeling of exotic scenery can all undergo a special experience [7].

Of course, network experience can also become a reality. In other words, you can actually go to the destination to have the actual experience, so that tourism activities in the virtual world came to reality. We can also make an organic integration between the two ways of tourism. As a result, cultural diversity and cross-cultural exchange will have more obvious effect.

\section{Conclusion}

With the acceleration of the process of modern informationization, information technology marked by the Internet has make the earth become a small village. The role played by emerging media in the era of modern "Internet + " is becoming more and more obvious. The importance of its position has become increasingly prominent day by day. Its functions in economic and social development have also become increasingly prominent. With modern Internet technology, the efficiency of modern information dissemination is getting higher and higher, especially the infiltration of various media by new media to all kinds of commercial media is even more advanced the process of globalization. In this context, what has been achieved is not only globalization of the economy, but also a broader space for cultural expansion and more internationalization and diversification. There is no doubt that the future of emerging media will be a newer attitude in the world, and future cultural exchange will take the platform of new media usher in a new situation. Emerging media, marked by greater openness and integration, are bound to do even more to ensure the diversity of human cultures and promote cross-cultural exchanges.

\section{References}

[1] Li Erjie. The Impact of Cultural Differences and Cross-cultural Exchanges on Commercial Activities - A Case Study of Enterprises in Coastal Cities and Mountainous Areas in Guangdong Province [J]. Journal of Mudanjiang University, 2012, 20 (09)

[2] Yulong Yu. On Cultural Exchanges [J]. Journal of Shenzhen University (Humanities and Social Sciences) 1987 (03)

[3] Ma Dong. Intercultural communication on the impact of ethnic cultures [J]. Heilongjiang Nationalities Series.2016 (02) 
[4] Ma Chi. "Transformation of space": a new horizon of intercultural communication [J]. Social Sciences Series .2014 (06)

[5] Dodd, C. H. Dynamics of intercultural communication. Dubuque, IA: Brown. 1991.

[6] Nieto, C. \& Booth, M. Cultural Competence: It's in fluence on the Teaching and Learning of International Students [J]. Journal of Studies in International Education, 2010 (4).

[7] Spiliotopoulos, Valia. Developing Multiliteracy in Adult ESL Learners Using On-line Forums [J]. The Humanities Collection, 2005. 